15

\title{
Получение гладких высокоточных поверхностей методом механического притира
}

\author{
() М.Н. Торопов, ${ }^{1}$ А.А. Ахсахалян, ${ }^{1}$ М.В. Зорина, ${ }^{1}$ Н.Н. Салащенко, ${ }^{1}$ Н.И. Чхало,,${ }^{1,}$ Ю.М. Токунов ${ }^{2}$ \\ ${ }^{1}$ Институт ффизики микроструктур РАН, \\ 607680 Нижний Новгород, Россия \\ ${ }^{2}$ Московский фризико-технический институт (МИФИ) \\ 141701 Долгопрудный, Московская обл., Россия \\ ` e-mail: chkhalo@ipm.sci-nnov.ru
}

Поступило в Редакцию 12 апреля 2020 г.

В окончательной редакции 12 апреля 2020 г.

Принято к публикации 12 апреля 2020 г.

Подробно описана методика получения высокоточных гладких сферических подложек с использованием механического притира и применяемая для этих целей метрология. Приведена модифицированная схема двухзондового интерферометра с дифракционной волной сравнения, обеспечивающая выравнивание интенсивности в плечах интерферометра и перестройку рабочей апертуры без перенастройки прибора. Представлены экспериментальные результаты, полученные при доводке с использованием этой методики вогнутой сферической подложки из плавленого кварца с числовой апертурой $\mathrm{NA}=0.30$, изготовленной традиционным методом глубокой шлифовки-полировки. Исходные характеристики подложки: точность формы по параметру СКО $=36 \mathrm{~nm}(\sim \lambda / 20)$, эффективной шероховатостью в диапазоне пространственных частот $0.025-65 \mu \mathrm{m}^{-1} \sigma_{\text {eff }}=1.1 \mathrm{~nm}$. После доводки подложки параметры поверхности улучшились до значений: $\mathrm{CKO}=3.3 \mathrm{~nm}(\sim \lambda / 200)$ и $\sigma_{\text {eff }}=0.26 \mathrm{~nm}$. Исследовано влияние размера зерна в суспензии на шероховатость и форму подложки.

Ключевые слова: притир, шлифовка-полировка, шероховатость, сферическая подложка.

DOI: $10.21883 /$ JTF.2020.11.49990.127-20

\section{Введение}

В связи с активным освоением экстремального ультрафиолетового и рентгеновского диапазонов длин волн, востребованных в таких областях, как проекционная нанолитография на длине волны $13.5 \mathrm{~nm}$ [1-4], изучение короны Солнца [5-9], микроскопия в спектральной области „окна прозрачности воды“ [10-14], синхротронные исследования $[15,16]$, появилась необходимость в создании оптики нового поколения с точностью формы на субнанометровом, а шероховатостью - на ангстремном уровне. Эти требования на один-два порядка выше, чем требования, предъявляемые к традиционной оптике. Проблема осложняется еще и тем, что требуются асферические поверхности.

Общеизвестно, что при шлифовке-полировке плоских и сферических поверхностей, благодаря взаимному притиру, достигается наилучшее качество обработки оптических поверхностей [17]. При изготовлении асферических поверхностей притир невозможен, а требуемая форма поверхности достигается за счет обработки малоразмерным инструментом. Отсутствие притира приводит к появлению локальных ошибок формы и шероховатостей, лежащих в диапазоне средних пространственных частот $\left(10^{-3}-1 \mu \mathrm{m}^{-1}\right)$. Поэтому при изготовлении высокоточных асферических поверхностей мы развиваем следующий подход. Первоначально методом притира изготавливаются сферические (плоские) подложки с радиусом кривизны, наиболее близким к требуемой асферике. Затем с использованием специально разработанной установки ионно-пучкового травления [18] проводятся коррекция локальных ошибок и асферизация формы $[19,20]$. Для этих целей исходными являются подложки-заготовки, представленные на рынке. Основным недостатком этих подложек является относительно невысокая точность изготовления, на уровне $\lambda / 30-\lambda / 20$, где $\lambda-$ рабочая длина волны интерферометра (чаще всего $632.8 \mathrm{~nm}$ ). Причиной этого является использование при метрологии интерферометров с эталонными поверхностями [21], которые обеспечивают высокую относительную (по отношению к эталону) точность измерений, однако систематические ошибки эталонов не учитываются.

В настоящей работе подробно описывается методика получения высокоточных гладких сферических подложек с использованием механического притира и применяемая для этих целей метрология. Представлены экспериментальные результаты, полученные при доводке методом механического притира вогнутой сферической подложки из плавленого кварца (диаметр $100 \mathrm{~mm}$, радиус кривизны $R_{\text {curv }}=137.5 \mathrm{~mm}$, числовая апертура $\mathrm{NA} \approx 0.3)$, изготовленной традиционным методом глубокой шлифовки полировки с точностью $\sim \lambda / 20$, до уровня $\sim \lambda / 200$. Описывается влияние среднего размера зерна используемой суспензии для полировки на шероховатость и форму подложки. 


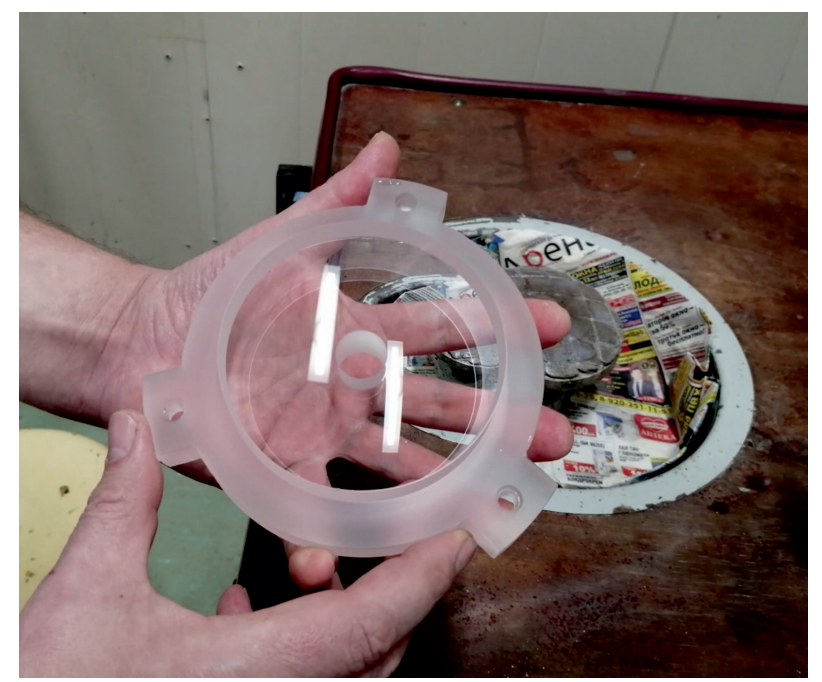

Рис. 1. Фото обрабатываемой подложки.

\section{1. Методика эксперимента}

\section{1. Методика механического притира}

Эксперимент проводился в специальной лаборатории, оснащенной кондиционированием воздуха, контролем температуры и влажности, что обеспечивало стабильность и воспроизводимость технологического процесса. Притир производился на доводочном станке Д-150. Шпиндель вращался от электромотора со средней скоростью „около“ $100 \mathrm{rpm}$. Деталь обрабатывалась поступательными движениями с амплитудой, определяемой опытным путем, для обеспечения исправления аберраций, ранее определенных посредством безэталонного интерферометра с дифракционной волной сравнения. Обработка поверхности велась смоляным полировальником (марка смолы СП5), поверхность которого в нагретом состоянии притиралась к обрабатываемой детали. В эксперименте использовались: водный раствор полирующего порошка широко используемой марки Opaline со средним размером зерна оксида церия $0.5-1 \mu \mathrm{m}$ и две суспензии на основе микропорошков оксида церия производства МФТИ, г. Долгопрудный, с размерами зерна $0.1-0.3$ и $0.03-0.1 \mu \mathrm{m}$.

Обрабатываемая подложка, фотография которой приведена на рис. 1, предназначена для разрабатываемого в настоящее время микроскопа с рабочей длиной волны $3.38 \mathrm{~nm}$, лежащей в „окне прозрачности воды“ [22]. Особенностью подложки является наличие трех „ушей“ с отверстиями. После завершения притира в отверстия вклеиваются полированные шарики из карбида кремния для установки зеркала в объектив. Такая конструкция подложки в отличие от подложек с металлическими „ушами“ [23] обладает лучшей устойчивостью к нагреву, который неизменно возникает при последующих стадиях ионно-пучковой обработки и напыления многослойного отражающего покрытия.

\section{2. Методы измерений шероховатости и формы}

Как отмечалось в ряде работ, например [23], в рентгеновском диапазоне на качество изображения и его освещенность оказывают влияние неровности (шероховатости) с латеральными размерами от диаметра зеркала до $1 \mathrm{~nm}$ (диапазон пространственных частот $\left.10^{-6}-10^{3} \mu \mathrm{m}^{-1}\right)$. Из-за столь широкого диапазона пространственных частот для полной характеризации поверхности его условно разделяют на три поддиапазона: низкочастотный (частоты $10^{-6}-10^{-3} \mu \mathrm{m}^{-1}$ ), среднечастотный $\left(10^{-3}-10^{0} \mu \mathrm{m}^{-1}\right)$ и высокочастотный $\left(10^{0}-10^{3} \mu \mathrm{m}^{-1}\right)$. Низкочастотные шероховатости (распространенное их название - ошибки формы) измеряются с использованием интерферометрии $[21,24]$. Для измерения среднечастотных шероховатостей традиционно используют интерферометры белого света (ИБС) $[25,26]$. Плоские образцы могут измеряться с помощью диффузного рассеяния рентгеновского излучения (ДРРИ) [27,28], которое при определенных условиях [29] можно отнести к „первопринципному“ методу. Следует отметить еще один метод измерения среднечастотных шероховатостей, использующий интерферометрию с дифракционной волной сравнения, который так же можно отнести к „первопринципному“, но который пока не нашел широкого распространения [30]. Для измерения высокочастотных шероховатостей применяются атомносиловые микроскопы (АСМ) [31].

Сравнение результатов измерений шероховатости подложек методами ИБС, АСМ и ДРРИ показало, что метод ИБС относительно неплохо работает только для подложек с эффективной шероховатостью больше $1 \mathrm{~nm}[32,33]$. Поэтому в своих исследованиях гладких поверхностей мы не используем этот метод.

Следует отметить, что АСМ также не относится к „первопринципному“ методу. На результаты измерений значительное влияние оказывают нелинейность пьезосканера, размер кончика и жесткость кантилевера. Поэтому периодически, а при использовании новой партии кантилеверов обязательно, производится калибровка чувствительности АСМ. Для этого для плоской гладкой подложки производится сравнение PSD (power spectral density - спектральная плотность мощности) функций шероховатости, измеренных методами АСМ и ДРРИ. Измерения признаются адекватными в том случае, если PSD-функции, измеренные обоими методами, совпадают в области пересечения их рабочих диапазонов. Измерения криволинейных поверхностей производятся на специальном стенде АСМ, позволяющем устанавливать локальную нормаль к поверхности исследуемой подложки в любой точке по оси зонда [34]. 


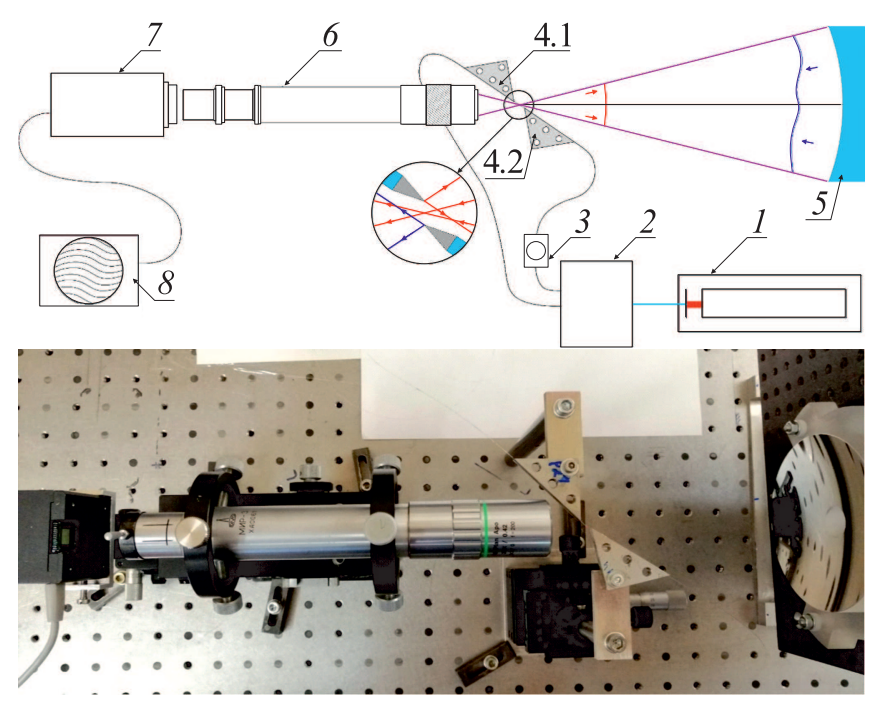

Рис. 2. Схема и фото интерферометра с дифракционной волной сравнения. $1-\mathrm{He}-\mathrm{Ne}-л а з е р, ~ 2-$ устройство (на фотографии не показано), включающее оптоволоконные делитель пучка и контроллеры поляризации света в каналах, 3 контроллер интенсивности света в канале эталонного фронта, 4.1 и 4.2 - ИЭСВ, 5 - исследуемая деталь, $6-$ оптическая часть регистрирующей системы, 7 - цифровая видеокамера, 8 - компьютер.

Как отмечалось ранее, низкочастотные шероховатости (они же ошибки формы) определяются с помощью интерферометров. Основным недостатком классических интерферометров является наличие эталона, ограничивающего точность измерений десятками нанометров, что препятствует как достижению нанометровой точности, так и развитию метода получения высокоточных поверхностей. Для решения этой проблемы была использована безэталонная интерферометрия с дифракционной волной сравнения на основе одномодового оптического волокна с субволновой выходной апертурой, позволяющая измерять форму даже асферических поверхностей с субнанометровой точностью [35].

В настоящей работе для исключения необходимости наносить на исследуемую деталь отражающее покрытие, обеспечивающее выравнивание интенсивности отраженного от детали и эталонного фронтов, за основу была взята двухзондовая схема интерферометра, предложенная в [36]. Модифицированная схема и фотография интерферометра с исследуемой деталью приведены на рис. 2. Излучение стабилизированного по частоте и мощности $\mathrm{He}-\mathrm{Ne}$-лазера 1 заводится в одномодовое оптическое волокно. Далее с помощью оптоволоконного делителя пучок разделяется на два канала, в каждом из которых с помощью оптоволоконного контроллера устанавливается одинаковая поляризация на выходе каждого канала 2. В канале эталонной сферической волны установлено устройство, позволяющее контролировать интенсивность света на выходе 3, что позволяет выравнивать интенсивности рабочего и эталонного фрон- тов при любом коэффициенте отражения исследуемой детали. К выходам обоих каналов подключаются когерентные между собой источники эталонной сферической волны (ИЭСВ, 4.1 и 4.2). Оба ИЭСВ устанавливаются в окрестности центра исследуемой сферической поверхности 5. Один из них направляется на исследуемую деталь, другой - на регистрирующую оптическую систему 6 . Отраженный от исследуемой поверхности фронт, несущий информацию об ошибках формы, фокусируется в окрестности ИЭСВ и далее в виде расходящегося сферического фронта распространяется в направлении регистрирующей системы. В регистрирующей системе рабочий и эталонный фронты интерферируют и регистрируются с помощью цифровой видеокамеры 7. Далее информация поступает в компьютер 8 .

Далее с помощью авторской программы по полученной серии из десяти интерферограмм восстанавливается карта отклонений формы поверхности от ближайшей сферы. Аппроксимация проводится с помощью полиномов Цернике [37]. Число членов в разложении определяется максимальной отображаемой пространственной частотой. При контроле обрабатываемой подложки в соответствии с [38] отображались неровности с латеральными размерами от $5 \mathrm{~mm}$ и выше.

Суммарный вклад в ошибку измерений аберраций ИЭСВ и оптической части регистрирующей системы оценивался по методике, описанной в [39], и составлял менее $1 \mathrm{~nm}$.

\section{3. Экспериментальные результаты}

Экспериментально исследовалось влияние размера микропорошка полирующей суспензии и времени полировки на шероховатость и форму поверхности. На рис. 3, $a$ приведены PSD-функции шероховатости исходной подложки, построенные по АСМ-кадрам $2 \times 2$ и $40 \times 40 \mu \mathrm{m}$. Эффективная шероховатость поверхности определялась из соотношения

$$
\sigma_{\mathrm{eff}}^{2}=\int_{\nu_{\min }}^{\nu_{\max }} \operatorname{PSD}(v) d v,
$$

где $v_{\min }=0.025 \mu \mathrm{m}^{-1}-$ минимальная и $v_{\max }=65 \mu \mathrm{m}^{-1}-$ максимальная пространственные частоты, и составила в среднем в 3-х точках $\sigma_{\text {eff }}=1.1 \pm 0.1 \mathrm{~nm}$.

Использование для притира водной суспензии Opalinec размером зерна $0.5-1 \mu \mathrm{m}$ в течение $2 \mathrm{~h}$ улучшило эффективную шероховатость до $0.66 \mathrm{~nm}$, дальнейшая полировка не приводила к улучшению шероховатости (рис. $3, b$ ).

После перехода на суспензию МФТИ с размером зерна $0.1-0.3 \mu \mathrm{m}$ шероховатость после суммарного времени полировки 6-7 h упала до величины $0.36 \mathrm{~nm}$. Дальнейшая полировка не приводила к улучшению шероховатости. PSD-функции шероховатости после полировки суспензией $0.1-0.3 \mu \mathrm{m}$ приведены на рис. $3, c$. 

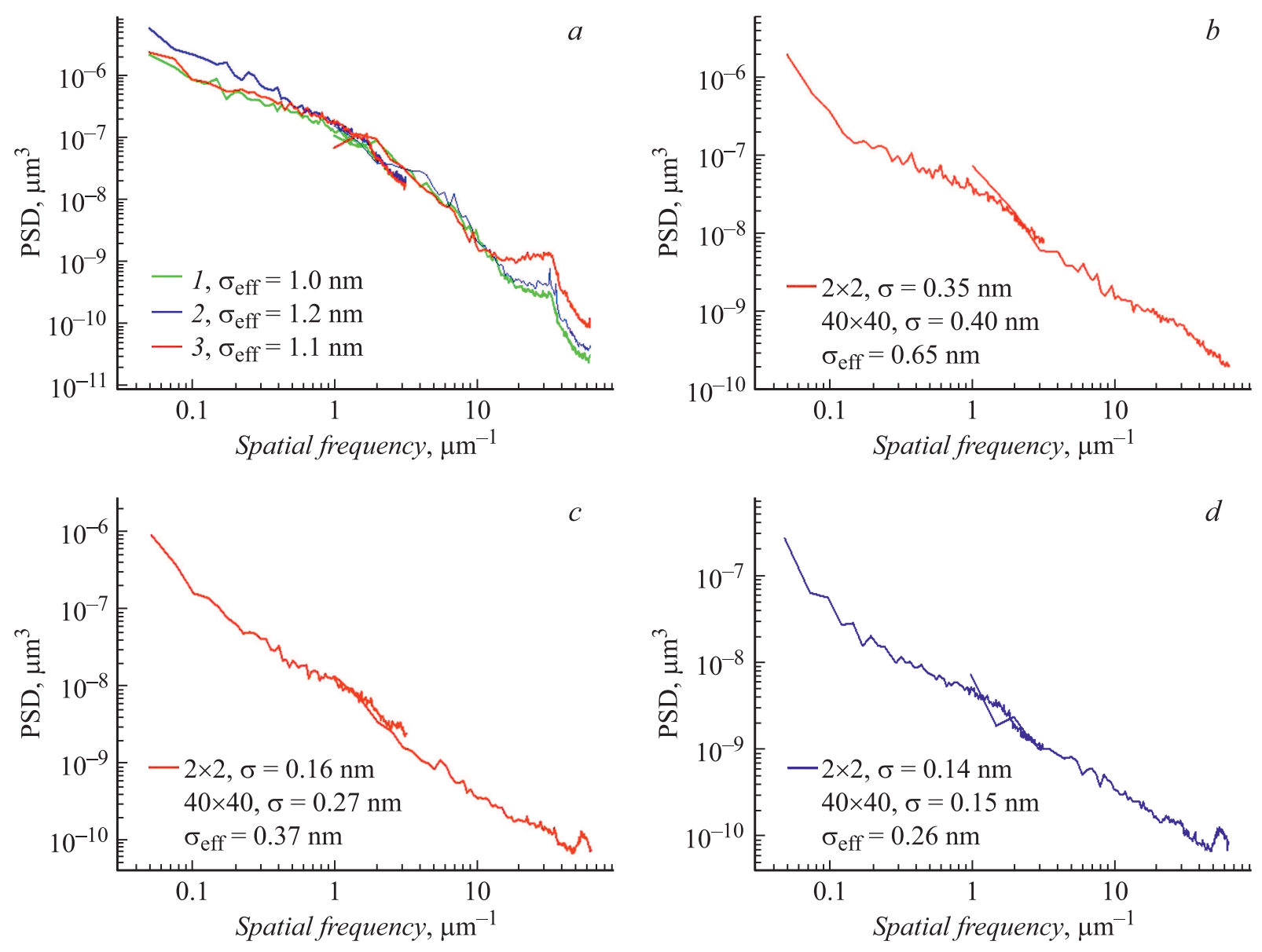

Рис. 3. PSD-функции шероховатости исходной подложки $(a)$, после полировки Opaline $(b)$, МФТИ $0.1-0.3 \mu \mathrm{m}(c)$ и МФТИ $0.03-0.1 \mu \mathrm{m}(d)$.

Переход на суспензию с размером зерна $0.03-0.1 \mu \mathrm{m}$ в первые $4 \mathrm{~h}$ обработки не приводил к сглаживанию поверхности, а затем в течение последующих $3 \mathrm{~h}$, она падала до величины $0.27 \mathrm{~nm}$ и стабилизировалась около этого значения (рис. $3, d$ ).

Из приведенных данных следует, что уменьшение размера зерна полирующей суспензии приводит к сглаживанию поверхности. При этом оптимальное время полировки при переходе на более мелкую фракцию составляет $6-7 \mathrm{~h}$. Дальнейшая полировка не приводит к улучшению шероховатости. В целом достигнутая при полировании суспензией МФТИ 0.03-0.1 $\mathrm{m}$ эффективная шероховатость $0.26 \mathrm{~nm}$ соответствует мировому уровню [33].

Важным результатом является то, что средне- и высокочастотные шероховатости вносят примерно одинаковый вклад в эффективную шероховатость. Это позволяет ожидать, что эффективная шероховатость может быть уменьшена почти в два раза после ионной полировки, которая наиболее эффективно сглаживает высокочастотные шероховатости [33,40-42].

Исследование влияния размера зерна суспензии и времени обработки на форму поверхности показало более сложный характер. В частности, оказалось, что ключевым звеном методики получения высокоточных поверхностей является время обработки. Эксперимент показал, что при подходе к точности формы на уровне $10 \mathrm{~nm}$ время обработки между последующими измерениями не должно превышать 20-30 min. При превышении времени обработки можно ожидать сильных скачков ошибок формы, на уровне $10 \mathrm{~nm}$ и больше.

Также при проведении интерферометрических измерений формы высокоточных поверхностей необходимо дать время на термостабилизацию подложки в интерферометре, которая может занять несколько часов, и следить за тем, чтобы исключить деформации поверхности при установке детали в интерферометр.

С учетом вышесказанного можно выделить определенные закономерности. Во-первых, размер зерна практически не влияет на точность формы, с той лишь оговоркой, что с увеличением размера зерна и в результате с увеличение скорости съема материала, необходимо сократить время обработки между измерениями. Вовторых, время выхода на стационарный уровень ошибки формы поверхности хорошо совпадает со временем, когда шероховатость выходит на стационарное значение. 

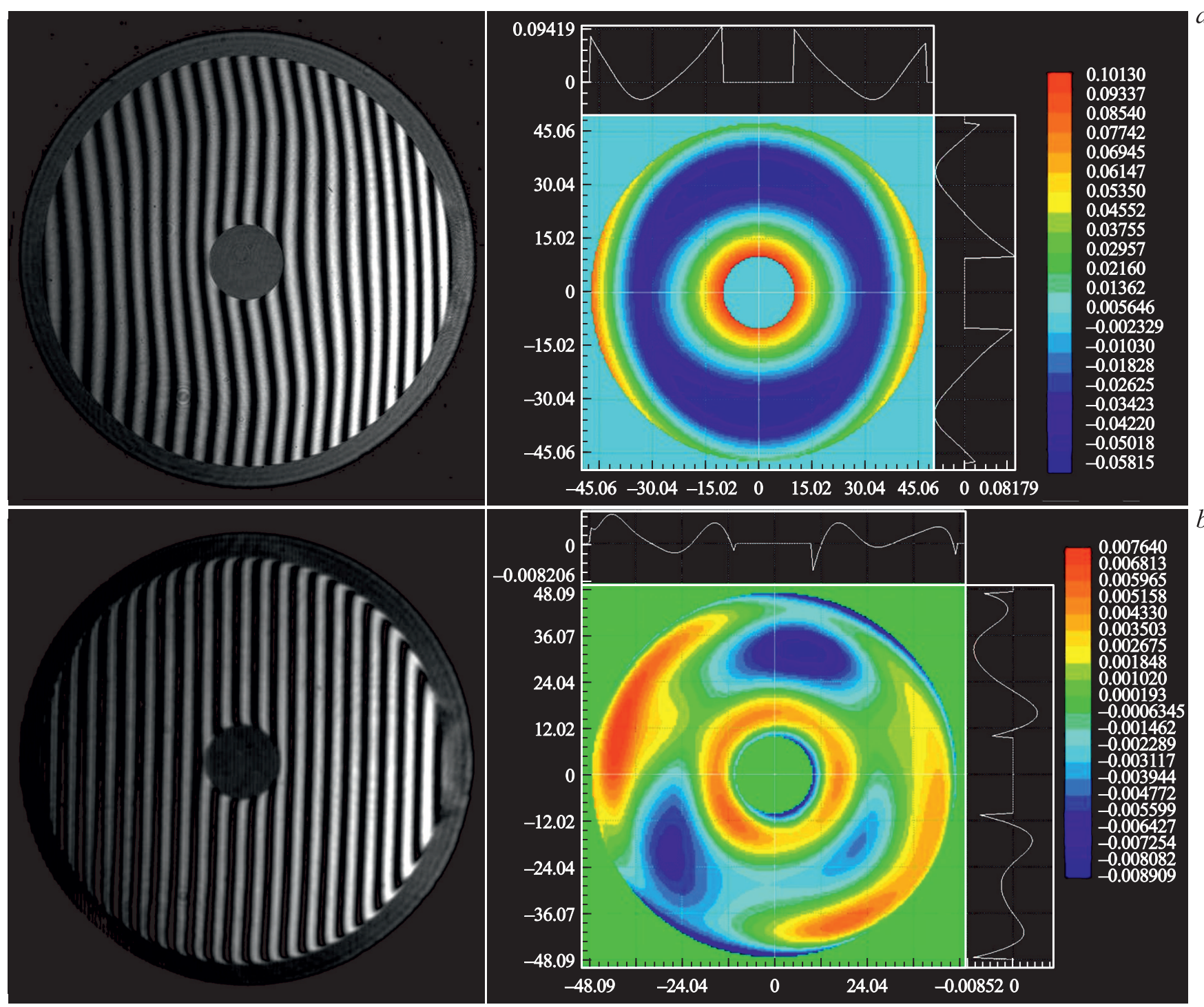

Рис. 4. Интерферограммы и карты формы поверхности подложки: исходная, максимальный размах $\mathrm{MP}=160 \mathrm{~nm}, \mathrm{CKO}=36 \mathrm{~nm}(a)$; после процедуры притира, $\mathrm{MP}=16.6 \mathrm{~nm}$ и $\mathrm{CKO}=3.3 \mathrm{~nm}(b)$.

В-третьих, при переходе с одного размера зерна на другое можно ожидать скачка в ошибке формы, причем скачок сильнее при переходе с меньшего зерна на большее.

В описанном эксперименте минимальная ошибка формы СКО $=3.3 \mathrm{~nm}(\sim \lambda / 200)$ была получена на суспензии $0.1-0.3 \mathrm{~nm}$. Однако и на суспензии $0.03-0.1 \mathrm{~nm}$ уверенно получаются близкие значения. На рис. 4 приведены карты ошибок исходной поверхности с СКО $=36 \mathrm{~nm}$ $(\sim \lambda / 20)-a$, и после доводки описанным методом $\mathrm{CKO}=3.3 \mathrm{~nm}(\sim \lambda / 200)-b$. Как видно, точность формы была увеличена на порядок.

\section{Заключение}

Несмотря на то, что метод механического притира для изготовления высокоточных сферических и плоских поверхностей используется уже несколько сотен лет тем не менее из-за ограниченных возможностей используемого в процессе производства и финальной аттестации изготовленной детали метрологического оборудования предельные возможности метода оставались не ясными. Применение интерферометрии с дифракционной волной сравнения, обеспечивающей достоверную точность измерений лучше $\lambda / 1000$, позволило продвинуться в область больших точностей.

Основными результатами настоящего исследования стало следующее.

Первое: показано, что относительно,легко“и „быстро“ методом механического притира можно изготавливать сферические подложки с точность формы на уровне $\lambda / 200$. Подробно описывается технологический процесс, позволяющий достичь этого результата. 
Второе: показано, что ключевым фактором получения высокоточных поверхностей является наличие „безэталонной“ интерферометрии. На основании ее данных было обнаружено, что длительность притира между измерениями должна быть минимальна и не превышать 20-30 min даже для самых мелкозернистых суспензий. Превышение этого времени может привести к большой (десятки нанометров) ошибке.

Третье: показано, что размер зерна слабо влияет на предельную точность изготавливаемых деталей.

Четвертое: прослежено влияние размера полирующего зерна суспензии на эффективную шероховатость поверхности. Наименьшая шероховатость (до $0.26 \mathrm{~nm}$ ) была получена при использовании суспензии производства МФТИ, г. Долгопрудный, с размером зерна оксида церия в суспензии $0.03-0.1 \mu \mathrm{m}$. Исходя из прослеженной динамики, следует, что можно еще уменьшить шероховатость, если использовать суспензию с меньшим размером зерна. Этот результат важен еще и с той точки зрения, что он был получен без использования химикомеханической полировки, которая негативно сказывается на точности формы поверхности.

Таким образом, описанный в работе метод позволяет относительно быстро получать подложки с нанометровой точностью формы поверхности и шероховатостью, соответствующей мировому уровню. Определены направления исследований для достижения ангстремной - субангстремной шероховатости, востребованной в ряде задач рентгеновской оптики.

\section{Финансирование работы}

Работа выполнена с использованием оборудования ЦКП ИФМ РАН, при поддержке Минобрнауки РФ в рамках Соглашения № 075-02-2018-182 (RFMEFI60418X0202).

\section{Конфликт интересов}

Авторы заявляют, что у них нет конфликта интересов.

\section{Список литературы}

[1] Wood O., Arnold J., Brunner T. et al. // Proc. SPIE. 2012. Vol. 8322. 832203.

[2] Mark N., Wurm S. // Adv. Opt. Technol. 2015. Vol. 4. N 4. P. 235-240. DOI: 10.1515/aot-2015-0036

[3] Wu B., Kumar A. // Appl. Phys. Rev. 2014. Vol. 1. P. 011104.

[4] Kim S.-S., Chalykh R., Kim H. et al. // Proc. SPIE. 2017. Vol. 10143. P. 1014306. DOI: 10.1117/12.2264043

[5] Golub L., Nystrom G., Herant M., Kalata K., Lovas I. // Nature. 1990. Vol. 344. P. 842-844.

[6] Kosugi T., Matsuzaki K., Sakao T. et al. // Sol. Phys. 2007. Vol. 243. N 1. P. 3-17.

[7] Pesnell W.D., Thompson B.J., Chamberlin P.C. // Sol. Phys. 2012. Vol. 275. N 1-2. P. 3-15.
[8] Kaiser M.L., Kucera T.A., Davila J.M., Cyr O.C.St., Guhathakurta M., Christian E. // Space Sci. Rev. 2008. Vol. 13. N 1-4. P. 5-16.

[9] Kobayashi K., Cirtain J., Winebarger A.R. et al. // Sol. Phys. 2014. Vol. 289. N 11. P. 4393-4412.

[10] Kirz J., Jacobsen C., Howells M. // Rev. Biophys. 1995. Vol. 28. P. 130.

[11] Takman P.A.C., Stollberg H., Johansson J.A. et al. // J. Microsc. 2007. Vol. 226. P. 175-181.

[12] Bertilson M., von Hofsten O., Vogt U. et al. // Opt. Express. 2009. Vol. 17. P. 11057-11065.

[13] Rehbein S., Heim S., Guttmann P. et al. // Phys. Rev. Lett. 2009. Vol. 103. N 11. P. 110801.

[14] Akhsakhalyan A.D., Kluenkov E.B., Lopatin A.Ya. // J. Surf. Invest.-X-Ray. 2017. Vol. 11. N 1. P. 1-19.

[15] Admans G., Berkvens P., Kaprolat A., Revol J.-L. ESRF upgrade programme phase II (2015-2022). Technical design study. Imprimerie de Pont de Claix, 2014. 192 p. http://www.esrf.eu/Apache_files/Upgrade/ESRF-orange-book.pdf

[16] Thiess H., Lasser H., Siewert F. // Nucl. Instrum. Meth. A. 2010. Vol. 616. P. 157-161.

[17] Смирнов В.А. Обработка оптического стекла. 3-е изд. Л.: Машиностроение, 1980. 183 с.

[18] Chkhalo N.I., Kaskov I.A., Malyshev I.V. et al. // Prec. Eng. 2017. Vol. 48. P. 338-346.

DOI: http://dx.doi.org/10.1016/j.precisioneng.2017.01.004

[19] Brychikhin M.N., Chkhalo N.I., Eikhorn Ya.O. // Appl. Opt. 2016. Vol. 55. N 16. P. 4430-4435.

[20] Chkhalo N.I., Malyshev I.V., Pestov A.E. et al. // J. Astron. Telesc. Instrum. Syst. 2018. Vol. 4. N 1. P. 014003-1-014003-9.

[21] Malacara D. Optical shop testing. 2nd ed. NY:: John Wiley\&Sons, Inc., 1992. 792 p.

[22] Malyshev I.V., Pestov A.E., Polkovnikov V.N. et al. // J. Surf. Invest.-X-Ray. 2018. Vol. 12. N 6. P. 1253-1263.

[23] Dinger U., Eisert F., Lasser H. et al. // Proc. SPIE. 2000. Vol. 4146. P. 35. DOI: http://dx.doi.org/10.1117/12.406674

[24] Окатов М.А., Антонов Э.А., Байгожсин А. и др. Справочник технолога-оптика / Под ред. М.А. Окатова. СПб.: Политехника, 2004. 679 с.

[25] Blunt R. // Proc. of CEMANTECH Conf. Vancouver, Canada, 2006. P. 59-62.

[26] Martinez-Galarce D., Soufli R., Windt D.L. et al. // Opt. Eng. 2013. Vol. 52. N 9. P. 095102-1-14.

[27] Kozhevnikov I.V., Pyatakhin M.V. // J. X-Ray Sci. Technol. 2000. Vol. 8. P. 253-275.

[28] Asadchikov V.E., Kozhevnikov I.V., Krivonosov Yu.S. et al. // Nucl. Instrum. Meth. A. 2004. Vol. 530. P. 575-595.

[29] Barysheva M.M., Chkhalo N.I., Drozdov M.N. et al. // J. X-Ray Sci. Technol. 2019. Vol. 27. N 5. P. 857-870. DOI: http://dx.doi.org/10.3233/XST-190495

[30] Svechnikov M.V., Chkhalo N.I., Toropov M.N. et al. // Opt. Lett. 2015. Vol. 40. N 2. P. 159-162.

[31] Griffith J.E., Grigg D.A. // J. Appl. Phys. 1993. Vol. 74. N 9. P. R83-R109.

[32] Barysheva M.M., Vainer Yu.A., Gribkov B.A. et al. // Bull. Russ. Acad. Sci. Phys. 2011. Vol. 75. N 1. P. 67-72.

[33] Chkhalo N.I., Churin S.A., Pestov A.E. et al. // Opt. Express. 2014. Vol. 22. N 17. P. 20094-20106.

[34] Chkhalo N.I., Salashchenko N.N., Zorina M.V. // Rev. Sci. Instrum. 2015. Vol. 86. P. 016102. 
[35] Chkhalo N.I., Malyshev I.V., Pestov A.E. et al. // Appl. Opt. 2016. Vol. 55. N 3. P. 619-625.

[36] Чхало Н.И., Малышев И.В., Пестов А.Е. и др. // УФН. 2020. T. 190. № 1. C. 74-91. https://doi.org/10.3367/UFNr.2019.05.038601.

[37] Mahajan V.N., Dai G.M. // J. Opt. Soc. Am. A. 2007. Vol. 24. N 9. P. 2994-3016.

[38] Svechnikov M.V., Chkhalo N.I., Toropov M.N., Salashchenko N.N. // Opt. Express. 2015. Vol. 23. N 11. P. 14677-14694.

[39] Ахсахалян А.А., Гаврилин Д.А., Малышев И.В. и др. // ЖТФ. 2019. Т. 89. Вып. 11. С. 1789-1794.

[40] Ziegler E., Peverini L., Vaxelaire N. et al. // Nucl. Instrum. Meth. A. 2010. Vol. 616. N 2-3. P. 188-192.

[41] Chen S., Li S., Peng X., Hu H., Tie G. // Appl. Opt. 2015. Vol. 54. N 6. P. 1478-1484.

[42] Chkhalo N.I., Churin S.A., Mikhaylenko M.S. et al. // Appl. Opt. 2016. Vol. 55. N 6. P. 1249-1256. 